\title{
Unravelling the one-carbon metabolism of the acetogen Sporomusa strain An4 by genome and proteome analysis
}

\author{
Michael Visser, ${ }^{1 *}$ Mervin M. Pieterse, ${ }^{2,3}$ \\ Martijn W. H. Pinkse, ${ }^{2,3}$ Bart Nijsse, ${ }^{4}$ \\ Peter D. E. M. Verhaert, ${ }^{2,3}$ Willem M. de Vos, ${ }^{1,5,6}$ \\ Peter J. Schaap ${ }^{4}$ and Alfons J. M. Stams ${ }^{1,7}$ \\ ${ }^{1}$ Laboratory of Microbiology and \\ ${ }^{4}$ Laboratory of Systems and Synthetic Biology, \\ Wageningen University, Stippeneng 4, 6708 WE \\ Wageningen, The Netherlands. \\ ${ }^{2}$ Department of Biotechnology, Technische Universiteit \\ Delft, Julianalaan 67, 2628 BC Delft, The Netherlands. \\ ${ }^{3}$ Netherlands Proteomics Centre, Julianalaan 67, 2628 \\ $B C$ Delft, The Netherlands. \\ Departments of ${ }^{5}$ Veterinary Biosciences and \\ ${ }^{6}$ Bacteriology and Immunology, Helsinki University, \\ Helsinki, Finland. \\ ${ }^{7}$ CEB-Centre of Biological Engineering, University of \\ Minho, Campus de Gualtar, 4710-057 Braga, Portugal.
}

\section{Summary}

The Sporomusa genus comprises anaerobic sporeforming acetogenic bacteria that stain Gramnegative. Sporomusa species typically grow with one-carbon substrates and $\mathrm{N}$-methylated compounds. In the degradation of these compounds methyltransferases are involved. In addition, Sporomusa species can grow autotrophically with $\mathrm{H}_{2}$ and $\mathrm{CO}_{2}$, and use a variety of sugars for acetogenic growth. Here we describe a genome analysis of Sporomusa strain An4 and a proteome analysis of cells grown under five different conditions. Comparison of the genomes of Sporomusa strain An4 and Sporomusa ovata strain H1 indicated that An4 is a $S$. ovata strain. Proteome analysis showed a high abundance of several methyltransferases, predominantly trimethylamine methyltransferases, during growth with betaine, whereas trimethylamine is one of the main end-products of betaine degradation. In methanol degradation methyltransferases are also involved. In methanol-utilizing methanogens, two

Received 2 April, 2015; revised 19 June, 2015; accepted 26 June, 2015. *For correspondence. E-mail: michael.visser@ wur.nl; Tel. 0317 483739. methyltransferases catalyse methanol conversion, methyltransferase 1 composed of subunits MtaB and MtaC and methyltransferase 2, also called MtaA. The two methyltransferase 1 subunits MtaB and MtaC were highly abundant when strain An4 was grown with methanol. However, instead of MtaA a methyltetrahydrofolate methyltransferase was synthesized. We propose a novel methanol degradation pathway in Sporomusa strain An4 that uses a methyltetrahydrofolate methyltransferase instead of MtaA.

\section{Introduction}

The genus Sporomusa was described in 1984 (Möller et al., 1984). It is a genus of motile spore-forming acetogenic bacteria that stain Gram-negative. Sporomusa strains have been isolated from soils and sediments (Möller et al., 1984; Hermann et al., 1987; Dehning et al., 1989; Sass et al., 1998), wastewater (Möller et al., 1984; Ollivier et al., 1989) and the gut and faeces of animals (Möller et al., 1984; Breznak and Switzer, 1986; Breznak et al., 1988; Boga et al., 2003). Currently, the genus Sporomusa consists of nine validated species. The characteristic substrates for Sporomusa species are onecarbon compounds, such as methanol, and N-methylated compounds such as betaine. In addition, they can grow autotrophically with $\mathrm{H}_{2}$ and $\mathrm{CO}_{2}$, and use a variety of sugars for acetogenic growth. Like other acetogenic bacteria, they employ the acetyl-coenzyme A (CoA) pathway for energy conservation and $\mathrm{CO}_{2}$ fixation (Drake et al., 1997; 2007).

Sporomusa strain An4 was isolated from an underground gas storage in Russia with methanol and perchlorate as substrates. Besides perchlorate, the strain was also able to use nitrate as electron acceptor. Unfortunately, in the course of this study, the strain lost its ability to use perchlorate as electron acceptor. The ability to respire with inorganic electron acceptors is not very common among Sporomusa species; only Sporomusa ovata and Sporomusa strain An4 have been described to reduce nitrate to ammonium (Möller et al., 1984; Balk et al., 2010). Sporomusa strain An4 is, according to phylogenetic analysis based on 16S rRNA gene 
sequences, closely related to Sporomusa strain DR5 and S. ovata strain $\mathrm{H} 1 \quad(99 \%$ and $98 \%$ sequence similarity respectively) (Balk et al., 2010).

Sporomusa strains are known to produce atypical corrinoids. More than $90 \%$ of the corrinoids in S. ovata consist of two synthesized coenzyme $B_{12}$ analogues: p-cresolyl cobamide and phenolyl cobamide (Stupperich et al., 1988; 1989; 1990). Some other studies provided insight into the transfer of the methyl group from methylated substrates to tetrahydrofolate (THF). For S. ovata the involvement of a cobamide-containing protein in the formation of methyl-tetrahydrofolate $\left(\mathrm{CH}_{3}-\right.$ THF) was shown (Stupperich and Konle, 1993). The synthesis of this protein was induced when S. ovata was grown on methanol. The cobamide-containing methyltransferase (MT) of S. ovata was purified and characterized (Stupperich et al., 1992; Wagner et al., 1994). Moreover, it was shown that different MTs are involved in degradation of different methylatedsubstrates (Stupperich and Konle, 1993) and cytochromes appeared to play a role in autotrophic growth and methyl group oxidation (Kamlage and Blaut, 1993). These and other studies (Dobrindt and Blaut, 1996; Wagner et al., 2000) gave insight into the physiology of Sporomusa.

Lack of genome information hampered further understanding of the metabolism of Sporomusa species. Only recently genomic information became available for S. ovata strain H1 (Poehlein et al., 2013). Here, we describe a comparison of the recently sequenced genome of $S$. ovata strain $\mathrm{H} 1$ and Sporomusa strain An4. Shotgun proteomics was applied to get insight into the catabolic pathways and the regulatory aspects of the metabolism of Sporomusa strain An4. Five different conditions were selected: acetogenic growth with $\mathrm{H}_{2}$ and $\mathrm{CO}_{2}$, methanol, betaine, and fructose; and respiratory growth with methanol and nitrate.

\section{Results}

Genome comparison of Sporomusa strain An4 and S. ovata strain $\mathrm{H} 1$

Whole genome shotgun sequencing combined with matepair sequencing of Sporomusa strain An4 resulted in $4.9 \mathrm{Mbp}$ assembled sequence data with an average scaffold size of $308 \mathrm{kbp}$. The draft genome was automatically annotated using the RAST Web service (Aziz et al., 2008). The genomes of Sporomusa strain An4 and S. ovata strain H1 (Poehlein et al., 2013) were compared at DNA level. The average nucleotide identity (ANI) was above $99 \%$. This ANI value is significantly higher than the 95-96\% ANI values shown to correspond to the $70 \%$ DNA-DNA hybridization level (Richter and Rossello-Mora, 2009). This indicates that Sporomusa strain An4 is a
S. ovata strain. The genome of Sporomusa strain An4 and strain $\mathrm{H} 1$ contained 5262 and 5110 protein-coding genes respectively. A domain analysis was performed to get insight into functional differences. The genome of the S. ovata strain $\mathrm{H} 1$ contained six domains that could not be found in the genome of strain An4. They are the domains of genes that code for two transposases, a protein of unknown function, an isopentenyl-diphosphate deltaisomerase and a toxin-antitoxin protein. The genome of strain An4 contained two domains that could not be found in the genome of $S$. ovata strain $\mathrm{H} 1$. The genes that contain these domains code for a multicopper oxidase (SpAn4DRAFT_0241) and a peptidase (SpAn4DRAFT_0978). The function of these proteins in strain An4 is currently not known.

\section{Acetogenesis and the acetyl-CoA pathway}

All genes coding for enzymes of the acetyl-CoA pathway were found to be present in the genome of Sporomusa strain An4 (Fig. 1). Many of these genes are situated in close proximity with each other in scaffold 4 , such as a methenyl-THF cyclohydrolase, methylene-THF dehydrogenase, the acetyl-CoA synthase operon and formate dehydrogenase (FDH) genes. The genes coding for the acetate kinase and the phosphate acetyltransferase are in other scaffolds. The genome of strain An 4 contains several genes that code for the same enzymes of the acetyl-CoA pathway, including formateTHF ligase (SpAn4DRAFT_2921, SpAn4DRAFT_4515), methenyl-THF cyclohydrolase (SpAn4DRAFT_2056, SpAn4DRAFT_2917), methylene-THF reductase (metF, SpAn4DRAFT_2800, SpAn4DRAFT_2934, SpAn4DRAFT_5207), acetyl-CoA synthase catalytic subunit (acsB, SpAn4DRAFT_2715, SpAn4DRAFT_ 2923 and SpAn4DRAFT_3609) and carbon monoxide dehydrogenase (CODH) catalytic subunit (cooS, SpAn4DRAFT_0020, SpAn4DRAFT_2714, SpAn4DRAFT_2922). The proteomic analysis showed peptide abundance of all enzymes of the acetyl-CoA pathway in all growth conditions (Fig. 2).

\section{One-carbon metabolism}

One-carbon compounds, for example carbon monoxide, formate and methanol, are characteristic growth substrates of Sporomusa species. Genes putatively coding for enzymes involved in one-carbon metabolism could be found in the genome of strain An4. Growth with CO requires a CODH. The genome of strain An4 contains three genes that putatively code for a $\mathrm{CODH}$ catalytic subunit (cooS, SpAn4DRAFT_0020, 2714, 2922). However, not all products of these genes can be found in the proteomics data (File S1). The proteomics data only 


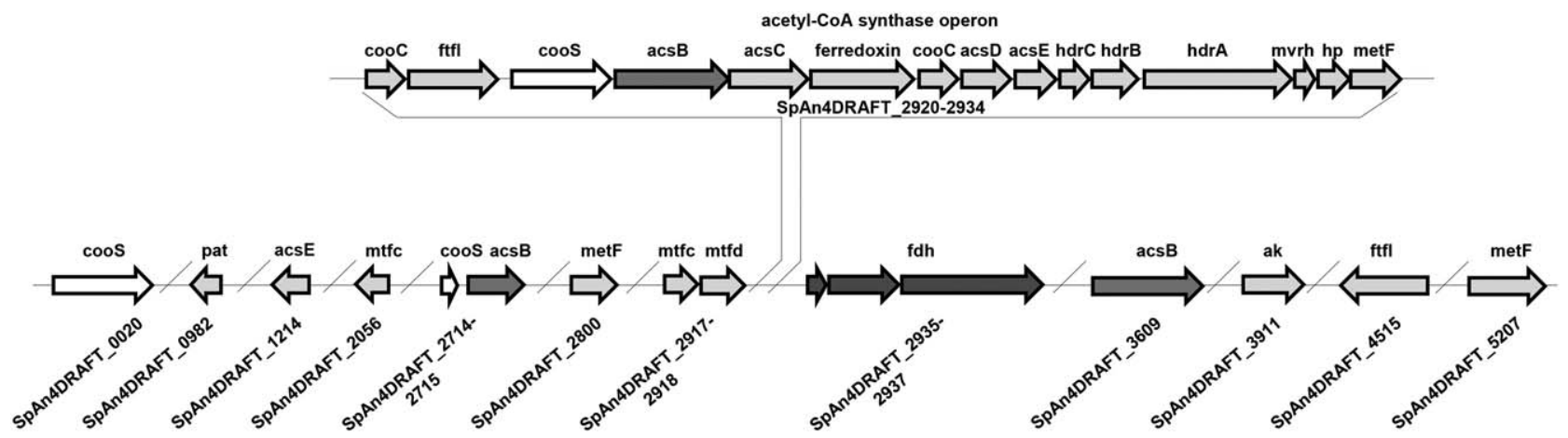

Fig. 1. Relative position of the acetyl-CoA synthase operon and genes of the acetyl-CoA pathway outside the operon. Scaffold and base pair numbers are located below the genes. Abbreviations are acsE: $\mathrm{CH}_{3}-\mathrm{THF}$ methyltransferase, ak: acetate kinase, fdh: formate dehydrogenase, ftfl: formate-THF ligase, hdr: heterodisulfide reductase, hp: hypothetical protein, mtfc: methenyl-THF cyclohydrolase, mtfd: methylene-THF dehydrogenase, mvrh: methyl viologen-reducing hydrogenase, pat: phosphate acetyltransferase.

show abundance of the gene product of the coos that is part of the acetyl-CoA synthase operon (SpAn4DRAFT_2922). This cooS is abundantly present in all growth conditions (Fig. 2).

Sporomusa strain An4 can grow with formate, and formate is also an intermediate of the acetyl-CoA pathway. The genome of strain An4 contains four putative FDHs, two dimeric cytoplasmic FDHs (SpAn4DRAFT_18771878, SpAn4DRAFT_5070-5071) and one dimeric extracytoplasmic FDH (SpAn4DRAFT_1889-1890); the small subunit contains a twin arginine consensus motif of Tat signal peptides involved in Sec-independent protein translocation, which suggests transport of the FDH complex across the cytoplasmic membrane. One trimeric cytoplasmic FDH (SpAn4DRAFT_2935-2937) contains a predicted ferredoxin and a nicotinamide adenine dinucleotide (NADH)-binding site, suggesting a possible bifurcating function as described by Wang and colleagues (2013). The latter FDH genes are situated upstream of the acetyl-CoA synthase operon (Fig. 1), and the products of these FDH genes were present in high abundance in the proteome analysis of all growth conditions (Fig. 2). The other two cytoplasmic FDHs were not detected in the proteome analysis, and the extracytoplasmic FDH (SpAn4DRAFT_1889-1890) only showed abundance in one of the five growth conditions (File S1). This suggests that the trimeric cytoplasmic FDH (SpAn4DRAFT_29352937) in strain An4 is the sole FDH involved in the acetylCoA pathway.

The genome of strain An4 contains a gene coding for an MT that is predicted to be methanol specific (SpAn4DRAFT_1215). The amino acid sequence of this putative MT was used for BLAST analysis to find homologues. BLAST results showed $99 \%$ coverage and $62 \%$ amino acid identity with the methanol: corrinoid MT, MtaB, of Moorella thermoacetica (Pierce et al., 2008). Another MT gene (SpAn4DRAFT_1216) is situated down- stream of the methanol MT in the genome of Sporomusa strain An4. This gene is homologous to the MT MtaC of M. thermoacetica, with $98 \%$ coverage and $45 \%$ amino acid identity. Situated upstream of the $m t a B$ homologue is a $\mathrm{CH}_{3}$-THF MT gene (SpAn4DRAFT_1214) and a gene coding for a cobalamin synthesis protein (SpAn4DRAFT_1213, Fig. 3).

In $M$. thermoacetica, the two genes $m t a B$ and $m t a C$ are known to code for two subunits of a methanol-specific MT (Zhou et al., 2005; Das et al., 2007). Another MT thought to be involved in the methanol metabolism in M. thermoacetica is encoded by a mtaA gene (Das et al., 2007; Pierce et al., 2008). Six possible $m t a A$ genes can be found in the genome of Sporomusa strain An4 (SpAn4_0190, 0193, 2181, 4129, 4142, 4143). BLASTX analysis showed that these six genes had $93-97 \%$ coverage and $24-31 \%$ amino acid identity with $M t a A$ in M. thermoacetica.

Proteome analysis revealed that the products of the two MT genes, $m t a B$ and $m t a C$, had a high protein abundance in strain An4 when grown with methanol (Fig. 2). However, none of the six possible mtaA homologues showed any abundance in the proteome of cells grown with methanol (File S1). Moreover, the gene product of the $\mathrm{CH}_{3}$-THF MT (SpAn4DRAFT_1214) gene upstream of the $m t a B$ showed high abundance when grown with methanol, suggesting its involvement in methanol metabolism.

The MtaC is a cobamide-binding protein. Cobamide biosynthesis and transport proteins in strain An4 were found in the proteome (File S1). More genes coding for MTs that function in a similar manner as the methanol MTs were found in the genome of strain An4. These include genes putatively coding for tri-, di- and monomethylamine (TMA, DMA and MMA respectively) MTs, which can be involved in the utilization of methylamines or the methyl groups of betaine (Möller et al., 1984; Andreesen, 1994; Krätzer et al., 2009). 
Predicted function

acetyl-CoA pathway

phosphate acetyltransferase

AcsB

MetF

methenyl-THF cyclohydrolase

methylene-THF dehydrogenase

$\mathrm{COOCI}$

formate-THF ligase

Coos

AcsB

ferredoxin

$\mathrm{CoOCII}$

ACSE (CH3-THF methyltransferase)

heterodisulfide reductase

methyl-viologen-reducing hydrogenase, delta subunit

zinc-finger protein

MetF

formate dehydrogenase

acsB

acetate kinase

formate-THF ligase

MetF

methanol metabolism

CH3-THF MT

MtaB

MtaC

betaine metabolism

$\mathrm{MttA} / \mathrm{Mtb} / \mathrm{MtmA}$

TMA MT

betaine reductase component $B$

L-seryl-tRNA(Sec) selenium transferase

glycine/sarcosine/betaine reductase component $C$

selenocysteine-specific translation elongation factor

selenide, water dikinase

glycine betaine transporter OpuD

glycine/sarcosine/betaine reductase protein $A$

glycine/sarcosine/betaine reductase component C

thioredoxin

thioredoxin reductase

TMA MT

glycine/sarcosine reductase component B

5-CH3THF homocysteine MT

$\mathrm{MttC}$

MttA/MtbA/MtmA

TMA MT

N5-CH3-tetrahydromethanopterin coM MT subunit H

$\mathrm{Mtt}$

\section{fructose metabolism}

fructose-bisphosphate aldolase

fructose-bisphosphate aldolase

pyruvate kinase

enolase

phosphoglycerate mutase

triosephosphate isomerase

phosphoglycerate kinase

NAD-dependent glyceraldehyde-3-phosphate dehydrogenase

fructose specific PTS system

1-phosphofructokinase

transcriptional repressor of the fructose operon

pyruvate-phosphate dikinase

\section{Nitrate respiration}

Nitrate reductase

CcmA

$\mathrm{CcmC}$

$\mathrm{CcmF}$

heme biosynthesis protein

nitrite reductase

hydroxylamine reductase

hydroxylamine reductase

NrfA
Locus tag

SpAn4DRAFT_0982

SpAn4DRAFT_2715

SpAn4DRAFT 2800

SpAn4DRAFT_2917

SpAn4DRAFT_2918

SpAn4DRAFT_2920

SpAn4DRAFT_ 2921

SpAn4DRAFT_2922

SpAn4DRAFT_ 2923

SpAn4DRAFT 2924

SpAn4DRAFT_2925

SpAn4DRAFT_2926

SPAn4DRAFT_2927

SpAn4DRAFT_2928

SpAn4DRAFT_2929-31

SpAn4DRAFT_2932

SpAn4DRAFT 2933

SpAn4DRAFT_2934

SpAn4DRAFT_2935-37

SpAn4DRAFT_3609

SpAn4DRAFT 3911

SpAn4DRAFT_4515

SpAn4DRAFT_5207

SpAn4DRAFT_1214

SpAn4DRAFT_1215

SpAn4DRAFT_ 1216

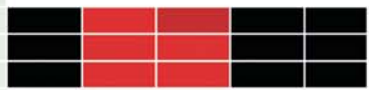

SPAn4DRAFT 0194

SpAn4DRAFT_0203-0

SpAn4DRAFT_2117-18

SpAn4DRAFT_2119

SpAn4DRAFT_2120-21

SpAn4DRAFT_2123

SpAn4DRAFT_2124

SpAn4DRAFT_ 2125

SpAn4DRAFT_2126

SpAn4DRAFT_2128-29

SpAn4DRAFT 2131

SpAn4DRAFT 2132

SpAn4DRAFT_2138-40

SpAn4DRAFT_2141-42

SpAn4DRAFT_2145

SpAn4DRAFT 2180

SpAn4DRAFT_2181

SPAn4DRAFT 2185-86

SpAn4DRAFT 2187

SpAn4DRAFT_2283

SpAn4DRAFT_0436 SpAn4DRAFT_0573 SpAn4DRAFT_0761

SpAn4DRAFT_1336

SpAn4DRAFT_1337

SpAn4DRAFT_1338

SpAn4DRAFT_1339

SpAn4DRAFT_1340

SpAn4DRAFT_2294-97

SpAn4DRAFT_2298

SpAn4DRAFT_2299

SpAn4DRAFT_5113

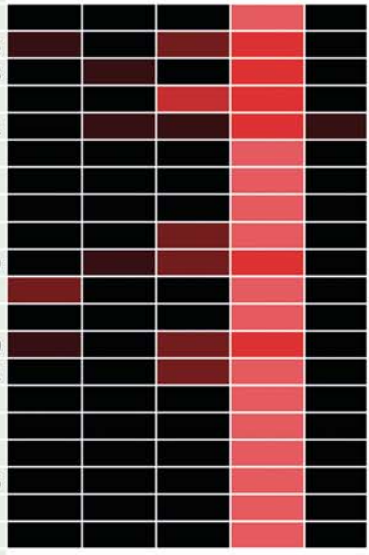

SpAn4DRAFT_3643-46 SpAn4DRAFT_3648 SpAn4DRAFT_3650

SpAn4DRAFT_ 3652

SpAn4DRAFT_3653

SpAn4DRAFT_3654

SpAn4DRAFT_3657

SpAn4DRAFT 4403

SpAn4DRAFT_4404
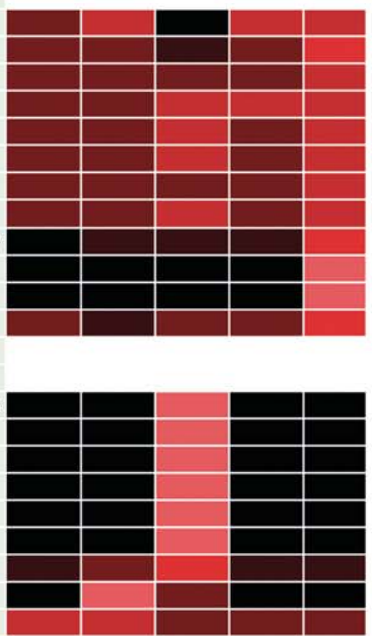
Fig. 2. Heatmap visualization of the proteomic data of proteins involved in the acetyl-CoA pathway, methanol metabolism, betaine metabolism and the selenocysteine incorporation system, fructose metabolism, and nitrate reduction, nitrite reduction and the biosynthesis of cytochrome c. The figure shows the predicted function of the proteins, the reference to the genome, and their related fractionation values in the five different growth conditions: hydrogen and carbon dioxide $\left(\mathrm{H}_{2} \mathrm{CO}_{2}\right)$, methanol (meoh), methanol and nitrate $\left(\mathrm{NO}_{3}{ }^{-}\right)$, betaine $(\mathrm{B})$, and fructose $(\mathrm{F})$. The fractionation values range between 0 and 1 and are calculated by comparing the peptide abundance of one protein of a condition to the total peptide count of all conditions.

\section{Betaine metabolism}

In Sporomusa species, betaine is reduced to TMA and acetyl phosphate. The electrons required for this reaction can be generated in the oxidation of methyl groups (Möller et al., 1984; Andreesen, 1994). The genome of Sporomusa strain An4 contains genes putatively coding for glycine/sarcosine/betaine reductase components A, B and $C$. The substrate specificity of the three different reductases of Eubacterium acidaminophilum is determined by the three different B components (Meyer et al., 1995). B components consist of an alpha and a beta subunit in an $\alpha_{2} \beta_{2}$ structure. Subunits GrdEB are described to be glycine specific, GrdGF sarcosine specific and GrdlH betaine specific (Meyer et al., 1995). We aligned the amino acid sequence of the $B$ components of E. acidaminophilum with those of Sporomusa strain An4 and constructed a neighbour-joining tree (File S2). The genome of An4 encodes two B components with an alpha and beta subunits. The two subunits of one $B$ component (SpAn4DRAFT_2118 and SpAn4DRAFT_2117) cluster together with the Grdl and GrdH of E. acidaminophilum, suggesting specificity for betaine. The other two genes of strain An4 (SpAn4DRAFT_2142 and SpAn4DRAFT_2141) do not cluster with either GrdB and GrdE or GrdF and GrdG, leaving the substrate specificity indistinct.

The proteome results indicated the synthesis of the glycine/sarcosine/betaine reductase components A, B and $C$ by strain An4 especially when grown with betaine (Fig. 2). This included both above-described substratespecific B components, suggesting that a betaine reductase and a sarcosine or glycine reductase are synthesized by strain An4. Additionally, a thioredoxin involved in these reductase-catalysed reactions was also detected in the proteome (Fig. 2).

The putative $A$ component and the beta subunit of the $B$ components in strain An4 are selenocysteine containing proteins. Selenocysteine incorporation into a protein requires the presence of a selenocysteine incorporation system (Fischer et al., 2007). Genes encoding such a system are present in the genome of strain An4. Additionally, the proteins involved in this system are synthesized by strain An4 (Fig. 2).

Many MTs showed high abundance during growth of strain An4 with betaine (Fig. 2). These MTs were predominantly TMA MTs. Two other MTs showed high abundance in betaine-grown cells, tetrahydromethanopterin S-MT subunit $\mathrm{H}$ (SpAn4DRAFT_2187) and a $\mathrm{CH}_{3}$ THF MT (SpAn4DRAFT_2145), indicating that they are involved in the betaine metabolism of Sporomusa strain An4.

\section{Hydrogen metabolism}

The genome of Sporomusa strain An4 contains four [FeFe] hydrogenases and three [NiFe] hydrogenases, divided in the following groups: one trimeric NADHbinding (possibly bifurcating as described by Schut and Adams, 2009) [FeFe] hydrogenase (SpAn4DRAFT_21152113); one trimeric membrane associated [FeFe] hydrogenase (SpAn4DRAFT_1380-1378), with a cytochrome $b$ as the membrane-associated subunit; two single [FeFe] hydrogenases, one is predicted to be cytoplasmic (SpAn4DRAFT_0657) and the other membrane associated (SpAn4DRAFT_2844); one dimeric membrane-linked [NiFe] hydrogenase (SpAn4DRAFT_ 2046-2045); one dimeric cytoplasmic [NiFe] hydrogenase (SpAn4DRAFT_0843-0844); and one trimeric membrane-associated hydrogenase (SpAn4DRAFT_ 3047-3049). The small subunit (SpAn4DRAFT_3049) of this hydrogenase contains a tat signal motif, which suggests transport of the complex across the cytoplasmic membrane. Moreover, the membraneassociated subunit is a putative four transmembrane helix containing cytochrome $b$. The proteome results showed protein abundance of the NiFe hydrogenase

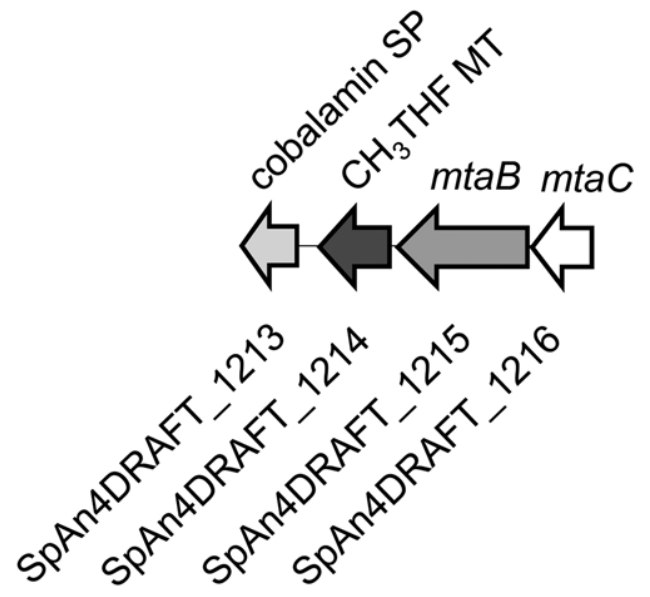

Fig. 3. Methyltransferase genes, $\mathrm{mtaB}$ and $\mathrm{mtaC}$, predicted to be involved in methanol-specific methyl transfer of Sporomusa strain An4, including a $\mathrm{CH}_{3}$-THF methyltransferase $\left(\mathrm{CH}_{3}\right.$-THF MT) and a cobalamin synthesis protein (cobalamin SP) upstream. 


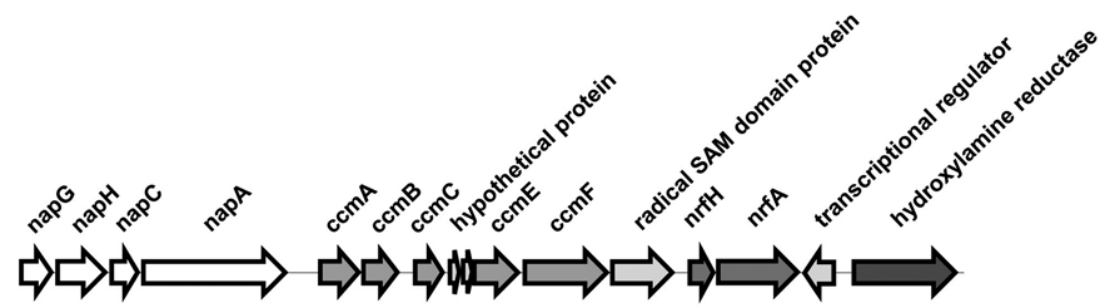

Fig. 4. Relative location of nitrate reduction genes, nitrite reduction genes, c type cytochrome biosynthesis genes and neighbouring genes in the Sporomusa strain An4 draft genome.

SpAn4DRAFT_3643-3657

(SpAn4DRAFT_3047-3049) and NADH-binding [FeFe] hydrogenase (SpAn4DRAFT_2115-2113) in all five growth conditions (File S1). No other hydrogenases were detected in the proteome.

\section{Sugar metabolism}

Sporomusa strain An4 was described, like S. ovata, to grow with fructose, but not with glucose (Balk et al., 2010). The genome of Sporomusa strain An4 contains all genes encoding the enzymes required for the conversion of fructose-6-phosphate to acetate. Additionally, the phosphotransferase system (PTS) necessary to transport fructose into the cell and simultaneously phosphorylate the sugar, to fructose-6-phosphate, is also encoded in the genome of strain An4. PTS complexes are also described for sugars other than fructose, for example glucose (Postma et al., 1993). The substrate specificity of these complexes is due to the PTS Ell proteins. On the basis of sequence alignment, Ells can be grouped into four classes: the glucose, mannitol/fructose, lactose and mannose classes (Postma et al., 1993). The genome of Sporomusa strain An4 contains genes encoding Ell proteins of the mannitol/fructose and lactose classes. Hence explains why strain An4 cannot grow with glucose. In addition, growth with mannitol or lactose is not possible because of the lack of genes in the genome coding for the enzymes degrading these compounds. Furthermore, no other sugar transporters or degradation enzymes are encoded in the genome of strain An4.

All enzymes necessary for fructose degradation were detected in the proteome analysis (Fig. 2).

\section{Electron acceptor metabolism}

Sporomusa strain An4, like S. ovata, reduces nitrate via nitrite to ammonium (Balk et al., 2010). In the genome of strain An4, genes coding for enzymes of nitrate reduction are present (Fig. 4). The napGHCA genes are positioned next to each other. Additionally, the $n r f H$ (SpAn4DRAFT_3654) and nrfA (SpAn4DRAFT_3655) genes are near the napGHCA cluster. Between the napGHCA cluster and the nrfHA nitrite reduction genes, the cytochrome $\mathrm{c}$ biosynthesis genes, $\operatorname{ccm} A$
(SpAn4DRAFT_3648), $\quad$ ccmB (SpAn4DRAFT_3649), ccmC (SpAn4DRAFT_3650), ccmE (SpAn4DRAFT_ 3651), and a ccmF gene (SpAn4DRAFT_3652) are positioned. Moreover, a hydroxylamine reductase gene (SpAn4DRAFT_3657) is upstream the nrfH and nrfA genes.

Another gene known to be involved in cytochrome $\mathrm{c}$ biosynthesis, $\operatorname{ccd} A$ gene, is also present in the genome of strain An4 (SpAn4DRAFT_3036). In addition, gene copies of the ccmA (SpAn4DRAFT_0162, SpAn4DRAFT_ 4410) ccmB (SpAn4DRAFT_0161, SpAn4DRAFT_4409), ccmC (SpAn4DRAFT_0160, SpAn4DRAFT_4408), ccmE (SpAn4DRAFT_0159, SpAn4DRAFT_4407), ccmF (SpAn4DRAFT_4406), nrfH (SpAn4DRAFT_4405), nrfA (SpAn4DRAFT_4404) and hydroxylamine reductase (SpAn4DRAFT_4403) are present in the genome.

Nitrate reductase, nitrite reductase, hydroxylamine reductase and cytochrome $\mathrm{c}$ biosynthesis proteins were all detected when strain An4 was grown with nitrate as electron acceptor (Fig. 2, File S1). These proteins are mainly encoded by the genes illustrated in Fig. 4. The function of hydroxylamine reductase in nitrate ammonification is not clear. However, hydroxylamine could be a product of nitrite reduction and be reduced to ammonium by hydroxylamine reductase as described in Nautilia profundicola AmH (Hanson et al., 2013).

\section{Enzyme activity measurements}

Additional enzyme activity measurements were performed on some of the key enzymes to relate the abundances of proteins determined by proteomics to protein function. Enzymes measured were $\mathrm{CODH}, \mathrm{FDH}$, nitrate reductase and nitrite reductase. Enzyme activity was measured in cell-free extract from cells grown with $\mathrm{H}_{2}$ and $\mathrm{CO}_{2}$, methanol and methanol plus nitrate. Enzyme activities were measured in Table 1, confirming their presence and functionality. Moreover, the nitrate reductase and the nitrite reductase activities were higher in cell-free extracts of cells grown with methanol and nitrate. This is in accordance with the higher peptide abundance of these proteins in the methanol with nitrate condition. Furthermore, the trimeric cytoplasmic FDH (SpAn4DRAFT_2935-2937) is the only FDH present in the proteome of the growth con- 
Table 1. Enzyme activity (in $\mathrm{U} / \mathrm{mg}$ and $\mathrm{U}=\mu \mathrm{mol} \mathrm{min}^{-1}$ ) measured from cell-free extracts of Sporomusa strain An4 cells grown with $\mathrm{H}_{2}$ and $\mathrm{CO}_{2}$, methanol (meoh), and methanol and nitrate $\left(\mathrm{NO}_{3}^{-}\right)$.

\begin{tabular}{|c|c|c|c|c|c|c|c|}
\hline Enzyme name & Reference to proteome/genome & $\mathrm{H}_{2} \mathrm{CO}_{2}$ & SD & $\mathrm{MeOH}$ & SD & NO3- & SD \\
\hline $\mathrm{CODH}$ & CooS/SpAn4DRAFT_2922 & $1.47(718)$ & 0.2 & $1.37(619)$ & 0.15 & $0.45(232)$ & 0.06 \\
\hline $\mathrm{FDH}$ & FDH alpha subunit/ SpAn4DRAFT_2937 & $2.44(756)$ & 0.18 & $2.2(751)$ & 0.2 & $1.86(574)$ & 0.15 \\
\hline $\mathrm{NO}_{3}{ }^{-}$reductase & NapA/SpAn4DRAFT_3646 & $0.55(0)$ & 0.11 & $0.77(0)$ & 0.13 & $5.88(170)$ & 0.18 \\
\hline $\mathrm{NO}_{2}^{-}$reductase & NrfA/SpAn4DRAFT_3655, SpAn4DRAFT_4404 & $0.37(5)$ & 0.15 & $0.51(1)$ & 0.07 & $8.1(177)$ & 0.2 \\
\hline
\end{tabular}

Enzymes measured included carbon monoxide dehydrogenase (CODH), formate dehydrogenase (FDH), nitrate reductase (NO3- reductase) and nitrite reductase (NO2- reductase). The activity values are averages of biological replicates (n3). Standard deviation (SD) between replicates are included. Moreover, reference to the proteome/genome is given, and the proteome data values are included in parentheses.

ditions used for enzyme activity measurements. It is, therefore, likely that the FDH activity is due to the presence of this enzyme (Table 1).

\section{Discussion}

Strain An4 was originally isolated with methanol and perchlorate. (Per)chlorate reduction was one of the physiological differences between strain An4 and S. ovata strain $\mathrm{H} 1$. Unfortunately, the strain had lost its ability to use perchlorate as electron acceptor before we could analyse the proteins involved. In Alicycliphilus denitrificans strain $\mathrm{BC}$ the chlorate reduction genes are located on a plasmid (Oosterkamp et al., 2013). Moreover, Clark and colleagues (2013) describe that chlorate reduction genes are flanked by insertion sequences. This suggests that the ability to reduce perchlorate is not necessarily genetically stable. Apparently, Sporomusa strain An4 lost genes involved in perchlorate reduction before the start of our experiments. The deposited DSM strain also was not able to reduce (per)chlorate.

\section{Genome comparison of Sporomusa strain An4 and S. ovata strain $\mathrm{H1}$}

Sporomusa strain An4 and S. ovata strain $\mathrm{H} 1$ are isogenic and the genome comparison showed only a few differences. The ANI value was above $99 \%$ and therefore it was concluded that An4 is a $S$. ovata strain. One of the differences is a multicopper oxidase, encoded by the genome of strain An4. Multicopper oxidases can couple the reduction of $\mathrm{O}_{2}$ to $\mathrm{H}_{2} \mathrm{O}$ with substrate oxidation (Rosenzweig and Sazinsky, 2006), but other enzymes involved in superoxide dismutation (MacPherson and Murphy, 2007), manganese oxidation (Butterfield et al., 2013), copper oxidation (in copper resistance) (Altimira et al., 2012) and nitrite reduction (MacPherson and Murphy, 2007) are also multicopper oxidases. However, none of these known enzymes shows high similarity to the multicopper oxidase of strain An4. Moreover, in strain An4, the proteome indicates the involvement of a cytochrome nitrite reductase and not a copper nitrite reductase. Furthermore, the multicopper oxidase is not detected in the proteome in any of the five tested conditions. Therefore, the function of the multicopper oxidase and why it is present in strain An4 and not in $\mathrm{S}$. ovata strain $\mathrm{H} 1$ cannot be deduced from our analysis.

\section{Proteogenomic analysis}

The proteome analysis resulted in 2280 proteins with 2 or more unique peptides. A total of 1162 of these proteins had a peptide abundance of at least 5 . High peptide abundance of a protein verifies synthesis by strain An4. The detected proteins included the enzymes necessary for growth with the selected growth conditions. Insight in the physiology of Sporomusa strain An4 was obtained by combining genome analysis with shotgun proteomics data. For example, the results indicate that one $\mathrm{FDH}$ (SpAn4DRAFT_2935-2937) is involved in the acetyl-CoA pathway in strain An4. The other FDHs present in the genome might be involved in for example growth with formate as a substrate.

Not all proteins that we expected to detect are present in the proteomics data. This can be due to the difference in the extraction of proteins; cytoplasmic proteins are easier to extract compared with membrane proteins, or to the size difference of proteins. Large proteins in general generate more peptides upon trypsin digestion and are, therefore, easier to detect. The catalytic subunit of nitrate reductase, NapA, obtains its electrons from the cytoplasmic membrane quinol pool by electron transport of either $\mathrm{NapC}$ or $\mathrm{NapGH}$. Both $\mathrm{NapC}$ and $\mathrm{NapGH}$ are quinol dehydrogenases (Brondijk et al., 2002, 2004; Kern and Simon, 2008; 2009; Simpson et al., 2010) and are present in the genome of strain An4. Although napC is present in the genome, its product was not found in the proteomics data. This could mean that either strain An4 only uses the NapGH quinol dehydrogenase complex to transport electrons to nitrate reductase $\mathrm{NapA}$, or the quinol dehydrogenase NapC was not detected because it is a small membrane protein.

In nitrate reduction, c-type cytochromes are important for the translocation of electrons. The biosynthesis of c-type cytochromes, also called the Ccm system, consists 


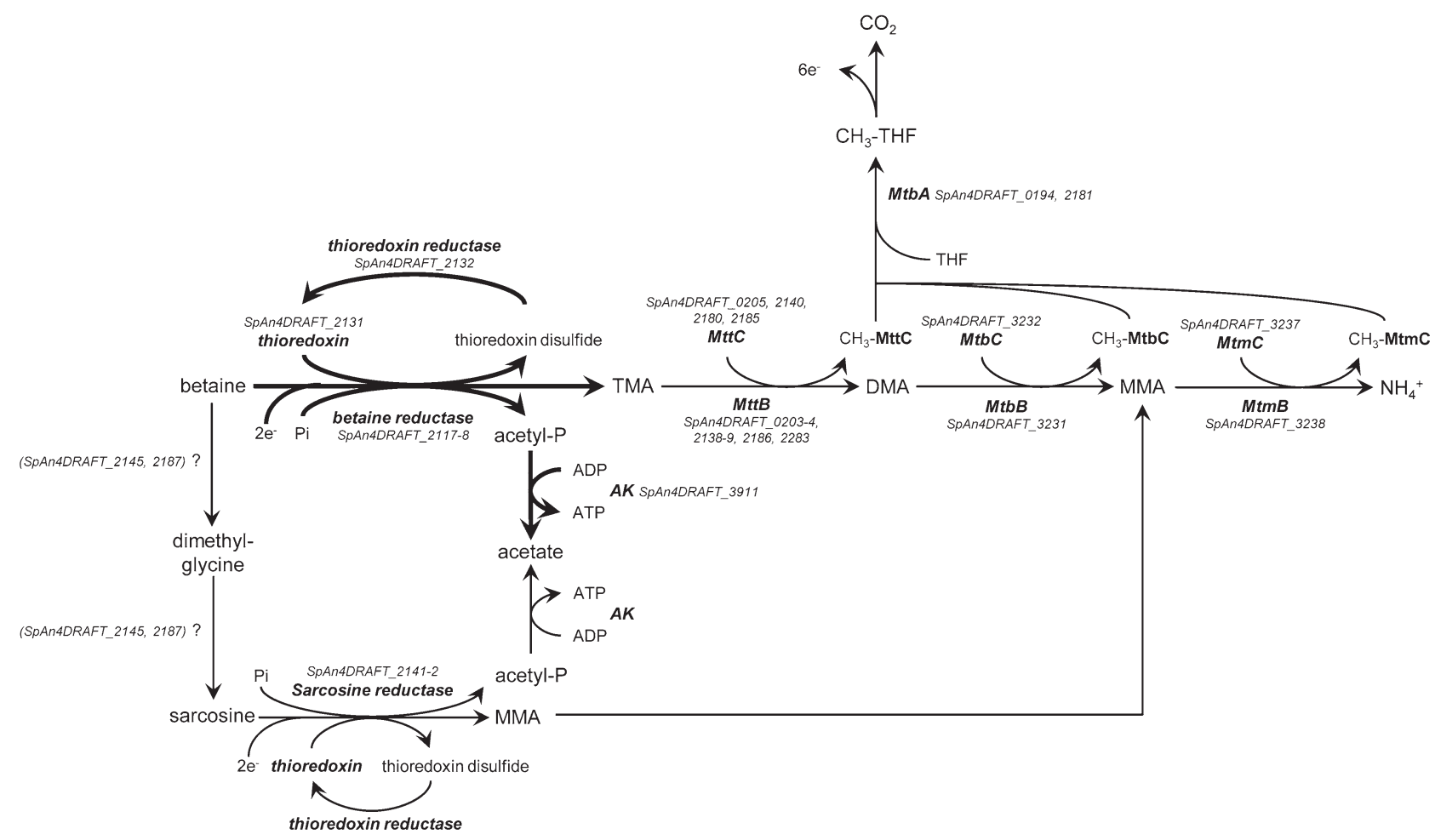

Fig. 5. Proposed betaine degradation pathway in Sporomusa strain An4. The thick arrows indicate the main degradation route, while the thin arrows represent reactions that generate electrons for the betaine reductase via the oxidation of methyl groups. Proteins are in bold italic and locus tags are in italic. Abbreviations: AK, acetate kinase; DMA, dimethylamine; $\mathrm{e}^{-}$, electron; MMA, monomethylamine; Pi, phosphate; TMA, trimethylamine.

of up to 10 components. These components are $\mathrm{CcmA}$ to $\mathrm{Ccml}$ and CcdA or DsbD (Sanders et al., 2010). In Sporomusa strain An4, only $\mathrm{CcmA}, \mathrm{CcmC}$ and $\mathrm{CcmF}$ protein levels were detected among the five conditions tested. CcmB, CcmE and CcdA are membrane proteins and therefore might have escaped detection.

Sporomusa strain An4 can grow with both sarcosine and glycine (Balk et al., 2010). Therefore, the substrate specificity of one of the highly abundant reductases (SpAn4DRAFT_2142-2141) during growth with betaine is unclear. Sporomusa ovata can only utilize sarcosine, not glycine, and produces methylamine, acetate and $\mathrm{CO}_{2}$, which suggest the involvement of a reductive cleavage reaction. Moreover, Möller and colleagues (1984) suggested that during growth with betaine, a small amount of betaine is demethylated to $\mathrm{N}, \mathrm{N}$ dimethyl-glycine. Subsequently, this N,N dimethyl-glycine was presumably demethylated further to sarcosine. This, together with the fact that the genome comparison between the two Sporomusa strains did not indicate that strain An4 uses a different reaction for sarcosine utilization, makes it likely that strain An4 uses a sarcosine reductase for betaine degradation and not a glycine reductase. Figure 5 shows the possible betaine degradation pathway in strain An4.

The proteome analysis shows high abundance of many MTs, predominantly TMA MTs, during growth with betaine. However, TMA is one of the main end-products of betaine degradation in Sporomusa species, including strain An4 (data not shown). The betaine reductase requires electrons that can be generated via the oxidation of methyl groups (Möller et al., 1984; Andreesen, 1994). The TMA MTs, the DMA MT and the MMA MT might be involved in the oxidation of small amounts of TMA to $\mathrm{NH}_{4}$ (Fig. 5). However, this does not explain the many TMA MTs that are synthesized during growth with betaine. We hypothesize that these TMA MTs bind different cobamides. Mok and Taga (2013) showed that in addition to $p$-cresolyl cobamide and phenolyl cobamide $S$. ovata can also produce other cobamides. Moreover, both Chan and Escalante-Semerena (2011) and Mok and Taga (2013) suggested that in S. ovata, there could be substrates that require enzymes that bind other cobamides than $p$-cresolyl cobamide and phenolyl cobamide. Sporomusa ovata is able to use externally supplied benzimidazoles to form benzimidazolyl cobamides. This inhibits methanol degradation because it interferes with the production of $p$-cresolyl cobamides (Mok and Taga, 2013). However, betaine degradation was not strongly affected by adding benzimidazoles, indicating less dependence on $p$-cresolyl cobamides, which could be explained if the different TMA MTs in S. ovata bind different cobamides. 


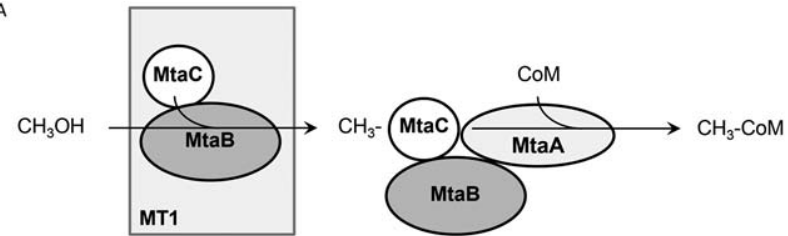

B

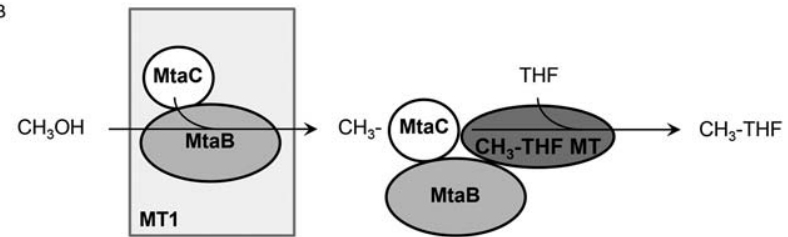

Fig. 6. Methanol conversion as described for a methanol utilizing methanogen $(A)$ and proposed methanol conversion in Sporomusa strain An4 (B). The AcsB subunit of methanol methyltransferase one (MT1) cleaves the $\mathrm{C}-\mathrm{O}$ bond of methanol and transfers the $\mathrm{CH}_{3}$ to the MtaC subunit. Subsequently, in the methanogenic pathway MtaA catalyses the transfer of the $\mathrm{CH}_{3}$ group to coenzyme M (CoM, A). In Sporomusa strain An4 the $\mathrm{CH}_{3}$-THF MT catalyses the transfer of the $\mathrm{CH}_{3}$ group to THF, creating $\mathrm{CH}_{3}-\mathrm{THF}(\mathrm{B})$.

Two other MTs, tetrahydromethanopterin S-MT subunit $\mathrm{H}$ and $\mathrm{C} \mathrm{CH}_{3}$ THF MT, also showed high abundances in the proteomics results during growth with betaine. The gene coding for the tetrahydromethanopterin S-MT subunit $\mathrm{H}$ is also present in the genome of $S$. ovata strain $\mathrm{H} 1$, but is designated as an MT 2. MtaA, MtmA, MtbA and MttA MTs are also of the MT 2 type. The tetrahydromethanopterin S-MT subunit $\mathrm{H}$ could, therefore, be involved in the methyl transfer from a corrinoid bound TMA MT to THF, or maybe these two MTs that have high abundance in strain An4 during growth with betaine are somehow involved in demethylation of betaine to sarcosine (Fig. 5). Clearly, growth with betaine leads to the synthesis of many MTs in Sporomusa strain An4 for which the exact function needs to be elucidated.

Degradation of methanol by $S$. ovata was described before. Stupperich and colleagues (1992) showed that a cobamide-binding methanol-specific MT was expressed by $S$. ovata and they hypothesized that the enzyme was involved in the cleavage of the $\mathrm{C}-\mathrm{O}$ bond of methanol, the transfer of the $\mathrm{CH}_{3}$ residue of methanol metabolism or both. Later, the $\mathrm{CH}_{3}$ group from methanol was found to be transferred to THF, creating $\mathrm{CH}_{3}$-THF and an entrance into the acetyl-CoA pathway (Stupperich and Konle, 1993). Transfer of the $\mathrm{CH}_{3}$ residue of methanol in methanogens was shown to be due to three enzyme subunits of the methanogenic methanol: coenzyme $M$ MT system. This system is composed of two MTs (van der Meijden et al., 1983; 1984). Methanol: 5-hydroxybenzimidazolylcobamide MT is the first MT and consists of two subunits, MtaB and MtaC, also known as methanol MT 1 (Sauer et al., 1997). MtaB catalyses the transfer of the $\mathrm{CH}_{3}$ group from methanol to a corrinoid bound to MtaC. The second MT consists of only one subunit (MtaA), which catalyses the transfer of the $\mathrm{CH}_{3}$ residue bound to MtaC to coenzyme $M$ (Fig. 6A, van der Meijden et al., 1983; 1984, Harms and Thauer, 1996, LeClerc and Grahame, 1996).

The proteomics results indicate no involvement of a MtaA homologue in methanol degradation by strain An4. Therefore, we propose a novel methanol metabolism without the involvement of an MtaA homologue. Instead of MtaA, the $\mathrm{CH}_{3}$-THF MT transfers the $\mathrm{CH}_{3}$ group bound to MtaC to THF (Fig. 6B).

Coenzyme $\mathrm{M}$ and THF are structurally different cofactors, hence it is logical that there is a different MT involved in methanogens compared with acetogens, MtaA for binding coenzyme $\mathrm{M}$ and $\mathrm{CH}_{3}$-THF MT for binding THF. Therefore, the methanol metabolism we propose for Sporomusa strain An4 could also be the methanol metabolism for other methanol utilizing acetogenic bacteria.

\section{Experimental procedures}

\section{Source of inoculum and culture medium}

Sporomusa strain An4 (=DSM 21435, =JSM 15643) was isolated from a water sample of an underground gas storage in Russia (Balk et al., 2010). The strain was enriched and isolated with methanol and perchlorate in a basal bicarbonate buffered medium described by Stams and colleagues (1993). The same medium but with the addition of $0.1 \mathrm{~g} \mathrm{l}^{-1}$ yeast extract was used in this study. The electron donors were added in $15 \mathrm{mM}$ concentrations and electron acceptors in $12 \mathrm{mM}$ concentration, from concentrated stock solutions (sterilized by autoclaving). Cultivation of strain An4 was done at neutral $\mathrm{pH}$ and $30^{\circ} \mathrm{C}$ in $117 \mathrm{ml}$ of glass serum vials with butyl rubber stoppers and aluminium crimp seals. The vials contained $50 \mathrm{ml}$ of basal medium and a gas phase of 1.7 bar $\mathrm{N}_{2} / \mathrm{CO}_{2}(80 \% / 20 \%$, v/v). When hydrogen was the electron donor, the gas phase was 1.7 bar $\mathrm{H}_{2} / \mathrm{CO}_{2}(80 \% / 20 \%$, v/v). In all experiments, the inoculum size was $10 \%(\mathrm{v} / \mathrm{v})$.

\section{Experimental design}

To obtain insight into the physiology of Sporomusa strain An4, a combined genome and proteome analysis was performed. For genome analysis, cells were grown with methanol. For proteome analysis, strain An4 was grown at five conditions with the following substrates: (1) hydrogen and carbon dioxide $\left(\mathrm{H}_{2}\right.$ and $\left.\mathrm{CO}_{2}\right)$, (2) methanol, (3) methanol and nitrate, (4) betaine and (5) fructose. Cells were adapted to the different growth conditions by transferring three times. Subsequently, $1.2 \mathrm{I}$ of bottles containing $500 \mathrm{ml}$ of medium were inoculated. Protein extraction of all growth conditions was performed at the late exponential phase.

\section{Analytical methods}

Organic compounds were quantified by high pressure liquid chromatography. Methanol, betaine, fructose and acetate 
were analysed using a MetaCarb $67 \mathrm{H} 5$ × $300 \mathrm{~mm}$ column (Varian, Middelburg, The Netherlands) connected to a SpectraSYSTEM RI-150 detector (Thermo Electron Corporation, Waltham, MA, USA). The $5 \mathrm{mM} \mathrm{H}_{2} \mathrm{SO}_{4}$ mobile phase had a flow of $0.8 \mathrm{ml} \mathrm{min}^{-1}$. The temperature was controlled at $30^{\circ} \mathrm{C}$ during the analysis. Crotonate was used as an internal standard.

Nitrate and nitrite were measured using an ED 40 electrochemical detector (Dionex, Breda, The Netherlands) after separation on an lonpac AS9-SC $4 \times 50 \mathrm{~mm}$ column (Dionex). Potassium fluoride ( $2 \mathrm{mM}$ ) was used as internal standard. The analysis was conducted at a temperature of $35^{\circ} \mathrm{C}$ with a flow rate of $1.2 \mathrm{ml} \mathrm{min}^{-1}$. The mobile phase used consisted of $1.29 \mathrm{~g} \mathrm{I}^{-1} \mathrm{Na}_{2} \mathrm{CO}_{3} \quad 10 \mathrm{H}_{2} \mathrm{O}$ and $0.12 \mathrm{~g} \mathrm{l}^{-1} \mathrm{NaHCO}_{3}$.

Hydrogen was analysed by gas chromatography with a Shimadzu GC-14B (Shimadzu, Kyoto, Japan) equipped with a packed column (Molsieve 13X, 60-80 mesh, 2 m length, $3 \mathrm{~mm}$ internal diameter; Varian) and a thermal conductivity detector set at $70 \mathrm{~mA}$. The injector temperature and the oven temperature were both $100^{\circ} \mathrm{C}$. The detector temperature was $150^{\circ} \mathrm{C}$. Argon was used as the carrier gas at a flow rate of $30 \mathrm{ml} \mathrm{min}^{-1}$.

Growth was measured by following the optical density of cultures at $600 \mathrm{~nm}\left(\mathrm{OD}_{600}\right)$ until the late exponential phase. Uninoculated medium served as a reference.

\section{DNA isolation, genome sequencing and genome annotation}

Genomic DNA from Sporomusa strain An4 was isolated using the standard Department of Energy Joint Genome Institute (DOE JGI) hexadecyltrimethylammonium bromide (CTAB) method. Sequencing the genome of strain An4 was done by using the 454 pyrosequencing technique and additional mate-pair sequencing (Droege and Hill, 2008). Shot-gun sequencing was performed to a redundancy of $44 \times(539893$ reads). The assembly of these reads was performed using the NEWBLER ASSEMBLER software (454 Life Sciences) resulting in 163 contigs of more than $500 \mathrm{bp}$. The additional Illumina mate-pair reads were used to extend the contigs and to create scaffolds by using SSPACE BASIC v2.0 (Boetzer et al., 2011) with a size insert derived from PICARDTOOLS. Gaps were filled with the mate-pair reads by using SSPACE GAPFILLING v1.11 (Boetzer and Pirovano, 2012). The final assembly was improved with PILON V1.4 using both 454 and mate-pair reads, which resulted in 16 scaffolds of more than $42 \mathrm{kbp}$. Scaffolds were reordered according to the S. ovata strain $\mathrm{H} 1$ draft genome. The 16 scaffolds were submitted to RAST server service (Aziz et al., 2008) for automatic annotation yielding 5264 protein encoding genes.

\section{Genome comparison}

The genome of Sporomusa strain An4 was compared with the genome of $S$. ovata strain $\mathrm{H} 1$ by analysing their functional domain profiles, which were obtained by first processing both genome assemblies with PRODIGAL (Hyatt et al., 2010) and subsequently using INTERPROSCAN 5 (version 5RC7, 27 January 2014). Differences are discussed in the text. The ANI of shared genes was used to determine the phylogenetic positioning of Sporomusa strain An4.

Comparison of selected Sporomusa strain An4 genes and putative proteins to other microorganisms than $S$. ovata was performed by BLAST analysis. Nucleotide sequences were compared with genes in the NCBI nucleotide collection database. The comparison was optimized for highly similar sequences. Amino acid sequences of selected strain An4 proteins were compared with proteins for homology, using the $\mathrm{NCBI}$ non-redundant protein sequence database, with default settings. For alignment, only amino acid sequences were used when the genome of the microorganism was fully sequenced. Additionally, the sequences required a minimum coverage of $80 \%$, and for alignment purposes, the minimum identity was at least $40 \%$. Alignment was performed using MUSCLE (Edgar, 2004).

To identify cofactor-binding motifs, transmembrane helices and twin-arginine translocation motifs in the $\mathrm{N}$-terminus, we used PFAM 27.0 (March 2013) (Punta et al., 2012), TMHMM SERVER v. 2.0 (Moller et al., 2001) and the TATP 1.0 SERVER (Bendtsen et al., 2005) respectively. Sequences with similarity to iron-only or [FeFe]-hydrogenases, were manually analysed for the presence of conserved $\mathrm{H}$-cluster residues (Vignais and Billoud, 2007). RNA loop prediction with MFOLD version 3.2. was used to predict incorporation of selenocysteine (Mathews et al., 1999; Zuker, 2003). We compared the predicted RNA loop in the 50-100 bp region downstream of the UGA-codon with the consensus loop described (Zhang and Gladyshev, 2005).

\section{Protein extraction}

For the preparation of protein samples $500 \mathrm{ml}$ of each growth condition was centrifuged at $26000 \times g$. The pellets were resuspended in sodium dodecyl sulfate dithiothreitol Tris (SDT) lysis buffer [100 mM Tris/HCl pH $7.6+4 \%$ SDS + 0.1M dithiothreitol (DTT)] and sonicated to disrupt the bacterial cell wall. Unbroken cells and debris were removed by centrifugation at $16000 \times g$ for $10 \mathrm{~min}$. Protein concentration in the samples was measured by using Bradford reagent (Sigma Aldrich, St. Louis, MO, USA) using bovine serum albumin as a standard.

\section{Proteome analysis}

For each growth condition, an equal amount of total protein was separated by SDS-PAGE on a 10-well PAGE® Novex 4-12\% Bis-Tris gel (Invitrogen) and ran using 2-(Nmorpholino)ethanesulfonic acid (MES)-SDS as running buffer for $30 \mathrm{~min}$ at a constant voltage of $200 \mathrm{~V}$. The gel was stained with Coomassie Blue (Colloidal Blue Staining Kit, Invitrogen) after which, the entire gel lanes were cut into 25 equal slices using a gridcutter (Gelcompany, SA, USA). Gel pieces were reduced with DTT $(10 \mathrm{mM}, 30 \mathrm{~min}$, room temperature), alkylated with iodoacetamide $(20 \mathrm{mM}, 60 \mathrm{~min}$, room temperature in the dark) and digested with trypsin overnight at $37^{\circ} \mathrm{C}$. After digestion, formic acid and dimethylsulphoxide were added (both $5 \% \mathrm{v} / \mathrm{v}$ ) to increase peptide recovery. Protein digests were analysed on a reversed phase nano-liquid chromatography (LC) coupled to an LTQ Orbitrap Velos (Thermo Fisher Scientific, Bremen, Germany). An Agilent 1200 series high-performance liquid chromatography system was equipped with in-house packed trapping column (100 $\mu \mathrm{m}$ ID and $20 \mathrm{~mm}$ length) and analytical column (50 $\mu \mathrm{m}$ ID and $250 \mathrm{~mm}$ length) filled with Reprosil 
Pur 120 C18-AQ (Dr. Maisch, Ammerbuch-Entringen, Germany) essentially as described by Meiring and colleagues (2002). Trapping was performed at $5 \mu \mathrm{l} / \mathrm{min}$ for $10 \mathrm{~min}$ in solvent $\mathrm{A}(0.1 \mathrm{M}$ acetic acid), and elution was achieved with a gradient from $0 \%$ to $40 \%$ solvent B $(0.1 \mathrm{M}$ acetic acid in 8:2 v/v acetonitrile : water) for $40 \mathrm{~min}$. The LTQ Orbitrap Velos was operated in data-dependent mode automatically switching between mass spectrometry (MS) and MS/MS. Survey full scan MS spectra were acquired from $\mathrm{m} / \mathrm{z}$ 400 to 1500 in the Orbitrap with a resolution of 30000 at $\mathrm{m} / \mathrm{z}$ 400 after accumulation to a target value of $1 \times 10^{6}$ in the linear ion trap. The 10 most intense, multiply charged ions at a threshold of above 1000 were fragmented in the linear ion trap using collision-induced dissociation at a target value of $1 \times 10^{4}$. All raw data files were processed into peaklists using PROTEOME DISCOVERER 1.1.

For each condition approximately 80000 to 100000 MS/MS spectra were obtained from trypsin-digested protein mixtures of cell-free extracts. The MS/MS spectra were submitted to a local implementation of the OMSSA search engine (Geer et al., 2004) and searched against a peptide database derived from the predicted proteins of the Sporomusa strain An4 draft genome RAST annotation. The following search parameters were used: a precursor ion tolerance of $0.03 \mathrm{Da}$, fragment ion tolerance of $0.5 \mathrm{Da}$, a miss cleavage allowance of up to and including 2. Cysteines were considered to be carboxyamidomethylated, oxidation of methionine, and deamination of glutamine and asparagine were treated as variable modifications. The set E-value threshold was determined iteratively from the false discovery rate (FDR) and was set to 0.01 . With this setting, an FDR of $<2 \%$ was obtained for all samples. The FDR was calculated from top hit spectral matches to peptides in the reversed database as described by Elias and Gygi (2007). The proteome analysis resulted in the identification of 2280 different proteins (with at least 2 unique peptides identified). Spectral counting (Liu et al., 2004) was used to study protein abundance. Higher counts lower the chance of false positives, making it more reliable that the protein is synthesized. A total of 1162 predicted proteins showed $>4$ counts and are listed in File S1. Proteins that possibly play an important role under different growth conditions are discussed in more detail in the text.

\section{Enzyme activity assays}

Enzyme activities of $\mathrm{CODH}, \mathrm{FDH}$, nitrate reductase and nitrite reductase were determined spectrophotometrically by measuring the colour change of methyl viologen (MV) at $578 \mathrm{~nm}$ and $37^{\circ} \mathrm{C}$, due to reduction or oxidation. Glass cuvettes were anaerobically prepared by flushing with $\mathrm{N}_{2}$, except for the CODH assay, where the glass cuvette was flushed with $\mathrm{CO}$. The $\mathrm{CODH}$ assay mixture contained $50 \mathrm{mM}$ 3-(N-morpholino)propanesulfonic acid- $\mathrm{KOH}(\mathrm{pH} 7), 1 \mathrm{mM}$ MV and $0.1 \mathrm{mM}$ DTT. The FDH assay mixture contained Tris- $\mathrm{HCl}(\mathrm{pH} 8), 1 \mathrm{mM} \mathrm{MV}, 0.1 \mathrm{mM}$ DTT and $10 \mathrm{mM}$ formate. In the CODH and FDH assay, the absorbance increased.

The nitrate and nitrite reductase assay mixture both contained $50 \mathrm{mM}$ Tris- $\mathrm{HCl}(\mathrm{pH} 7.5), 0.5 \mathrm{mM} \mathrm{MV}$, a small amount of dithionite solution to reach a starting absorbance of approximately 1.5 , and $4 \mathrm{mM}$ nitrate or $0.25 \mathrm{mM}$ nitrite respectively.

\section{Acknowledgements}

Research was funded by grants of the Division of Chemical Sciences (CW-TOP 700.55.343) and Earth and Life Sciences (ALW 819.02.014) and the 2008 Spinoza Award of The Netherlands Organisation for Scientific Research (NWO), and of The Netherlands Proteomics Centre embedded in The Netherlands Genomics Initiative. A.J.M. Stams and W.M. de Vos acknowledge the financial support of ERC grants (323009 and 250172) and the Gravitation grant (024.002.002) of the Netherlands Ministry of Education, Culture and Science.

\section{References}

Altimira, F., Yáñez, C., Bravo, G., González, M., Rojas, L.A., and Seeger, M. (2012) Characterization of copper-resistant bacteria and bacterial communities from copper-polluted agricultural soils of central Chile. BMC Microbiol 12: 193204.

Andreesen, J.R. (1994) Glycine metabolism in anaerobes. Antonie Van Leeuwenhoek 66: 223-237.

Aziz, R.K., Bartels, D., Best, A.A., DeJongh, M., Disz, T., Edwards, R.A., et al. (2008) The RAST Server: rapid annotations using subsystems technology. BMC Genomics 9: 75.

Balk, M., Mehboob, F., van Gelder, A.H., Rijpstra, I.C., Sinninghe Damsté, J.S., and Stams, A.J.M. (2010) (Per)chlorate reduction by an acetogenic bacterium, Sporomusa sp., isolated from an underground gas storage. Appl Microbiol Biotechnol 88: 595-603.

Bendtsen, J.D., Nielsen, H., Widdick, D., Palmer, T., and Brunak, S. (2005) Prediction of twin-arginine signal peptides BMC. Bioinformatics 6: 167.

Boetzer, M., and Pirovano, W. (2012) Toward almost closed genomes with GapFiller. Genome Biol 13: R56.

Boetzer, M., Henkel, C.V., Jansen, H.J., Butler, D., and Pirovano, W. (2011) Scaffolding preassembled contigs using SSPACE. Bioinformatics 27: 578-579.

Boga, H.I., Ludwig, W., and Brune, A. (2003) Sporomusa aerivorans sp. nov., an oxygen-reducing homoacetogenic bacterium from the gut of a soil-feeding termite. Int J Syst Evol Microbiol 53: 1397-1404.

Breznak, J.A., and Switzer, J.M. (1986) Acetate synthesis from $\mathrm{H}_{2}$ plus $\mathrm{CO}_{2}$ by termite gut microbes. Appl Environ Microbiol 52: 623-630.

Breznak, J.A., Switzer, J.M., and Seitz, H.J. (1988) Sporomusa termitida sp. nov., an $\mathrm{H}_{2} / \mathrm{CO}_{2}$-utilizing acetogen isolated from termites. Arch Microbiol 150: 282-288.

Brondijk, T.H., Fiegen, D., Richardson, D.J., and Cole, J.A. (2002) Roles of NapF, NapG and $\mathrm{NapH}$, subunits of the Escherichia coli periplasmic nitrate reductase, in ubiquinol oxidation. Mol Microbiol 44: 245-255.

Brondijk, T.H., Nilavongse, A., Filenko, N., Richardson, D.J., and Cole, J.A. (2004) NapGH components of the periplasmic nitrate reductase of Escherichia coli K-12: location, topology and physiological roles in quinol oxidation and redox balancing. Biochem $J$ 379: 47-55.

Butterfield, C.N., Soldatova, A.V., Lee, S.W., Spiro, T.G., and Tebo, B.M. (2013) $\mathrm{Mn}(\mathrm{II}, \mathrm{III})$ oxidation and $\mathrm{MnO}_{2}$ mineralization by an expressed bacterial multicopper oxidase. Proc Natl Acad Sci USA 110: 11731-11735. 
Chan, C.H., and Escalante-Semerena, J.C. (2011) ArsAB, a novel enzyme from Sporomusa ovata activates phenolic bases for adenosylcobamide biosynthesis. Mol Microbiol 81: 952-967.

Clark, I.C., Melnyk, R.A., Engelbrektson, A., and Coates, J.D. (2013) Structure and evolution of chlorate reduction composite transposons. MBio 4: e00379-13.

Das, A., Fu, Z.Q., Tempel, W., Liu, Z.J., Chang, J., Chen, L., et al. (2007) Characterization of a corrinoid protein involved in the $\mathrm{C} 1$ metabolism of strict anaerobic bacterium Moorella thermoacetica. Proteins 67: 167-176.

Dehning, I., Stieb, M., and Schink, B. (1989) Sporomusa malonica sp. nov., a homoacetogenic bacterium growing by decarboxylation of malonate or succinate. Arch Microbiol 151: 421-426.

Dobrindt, U., and Blaut, M. (1996) Purification and characterization of a membrane-bound hydrogenase from Sporomusa sphaeroides involved in energy-transducing electron transport. Arch Microbiol 165: 141-147.

Drake, H.L., Daniel, S.L., Küsel, K., Matthies, C., Kuhner, C., and Braus-Stromeyer, S. (1997) Acetogenic bacteria: what are the in situ consequences of their diverse metabolic versatilities? Biofactors 6: 13-24.

Drake, H.L., Gößner, A.S., and Daniel, S.L. (2007) Old acetogens, new light. Ann N Y Acad Sci 1125: 100-128.

Droege, M., and Hill, B. (2008) The Genome Sequencer FLX System-longer reads, more applications, straight forward bioinformatics and more complete data sets. J Biotechnol 136: 3-10.

Edgar, R.C. (2004) MUSCLE: multiple sequence alignment with high accuracy and high throughput. Nucleic Acids Res 32: 1792-1797.

Elias, J.E., and Gygi, S.P. (2007) Target-decoy search strategy for increased confidence in large-scale protein identifications by mass spectrometry. Nat Methods 4: 207214.

Fischer, N., Paleskava, A., Gromadski, K.B., Konevega, A.L., Wahl, M.C., Stark, H., and Rodnina, M.V. (2007) Towards understanding selenocysteine incorporation into bacterial proteins. Biol Chem 388: 1061-1067.

Geer, L.Y., Markey, S.P., Kowalak, J.A., Wagner, L., Xu, M., Maynard, D.M., et al. (2004) Open mass spectrometry search algorithm. J Proteome Res 3: 958-964.

Hanson, T.E., Campbell, B.J., Kalis, K.M., Campbell, M.A., and Klotz, M.G. (2013) Nitrate ammonification by Nautilia profundicola $\mathrm{AmH}$ : experimental evidence consistent with a free hydroxylamine intermediate. Front Microbiol 4: 180.

Harms, U., and Thauer, R.K. (1996) Methylcobalamin: coenzyme $M$ methyltransferase isoenzymes MtaA and MtbA from Methanosarcina barkeri. Cloning, sequencing and differential transcription of the encoding genes, and functional overexpression of the mtaA gene in Escherichia coli. FEBS J 235: 653-659.

Hermann, M., Popoff, M.R., and Sebald, M. (1987) Sporomusa paucivorans sp. nov., a methylotrophic bacterium that forms acetic acid from hydrogen and carbon dioxide. Int J Syst Bacteriol 37: 93-101.

Hyatt, D., Chen, G.L., Locascio, P.F., Land, M.L., Larimer, F.W., and Hauser, L.J. (2010) Prodigal: prokaryotic gene recognition and translation initiation site identification. $B M C$ Bioinformatics 11: 119.
Kamlage, B., and Blaut, M. (1993) Isolation of a cytochromedeficient mutant strain of Sporomusa sphaeroides not capable of oxidizing methyl groups. J Bacteriol 175: 30433050.

Kern, M., and Simon, J. (2008) Characterization of the $\mathrm{NapGH}$ quinol dehydrogenase complex involved in Wolinella succinogenes nitrate respiration. Mol Microbiol 69: 1137-1152.

Kern, M., and Simon, J. (2009) Periplasmic nitrate reduction in Wolinella succinogenes: cytoplasmic NapF facilitates NapA maturation and requires the menaquinol dehydrogenase $\mathrm{NapH}$ for membrane attachment. Microbiology 155: 2784-2794.

Krätzer, C., Carini, P., Hovey, R., and Deppenmeier, U. (2009) Transcriptional profiling of methyltransferase genes during growth of Methanosarcina mazei on trimethylamine. J Bacteriol 191: 5108-5115.

LeClerc, G.M., and Grahame, D.A. (1996) Methylcobamide: coenzyme $M$ methyltransferase isozymes from Methanosarcina barkeri. Physicochemical characterization, cloning, sequence analysis, and heterologous gene expression. Eur J Biochem 271: 18725-18731.

Liu, H., Sadygov, R.G., and Yates, J.R. (2004) A model for random sampling and estimation of relative protein abundance in shotgun proteomics. Anal Chem 76: 41934201.

MacPherson, I.S., and Murphy, M.E.P. (2007) Type-2 coppercontaining enzymes. Cell Mol Life Sci 64: 2887-2899.

Mathews, D.H., Sabina, J., Zuker, M., and Turner, D.H. (1999) Expanded sequence dependence of thermodynamic parameters improves prediction of RNA secondary structure. J Mol Biol 288: 911-940.

van der Meijden, P., Heythuysen, H.J., Pouwels, A., Houwen, F., van der Drift, C., and Vogels, G.D. (1983) Methyltransferases involved in methanol conversion by Methanosarcina barkeri. Arch Microbiol 134: 238-242.

van der Meijden, P., te Brömmelstroet, B.W., Poirot, C.M., van der Drift, C., and Vogels, G.D. (1984) Purification and properties of methanol: 5-hydroxybenzimidazolylcobamide methyltransferase from Methanosarcina barkeri. $J$ Bacteriol 160: 629-635.

Meiring, H.D., van der Heeft, E., and ten Hove, G.J. (2002) Nanoscale LC-MS(n): technical design and applications to peptide and protein analysis. J Sep Sci 25: 557-568.

Meyer, M., Granderath, K., and Andreesen, J.R. (1995) Purification and characterization of protein $\mathrm{P}$, of betaine reductase and its relationship to the corresponding proteins glycine reductase and sarcosine reductase from Eubacterium acidaminophilum. Eur J Biochem 234: 184191.

Mok, K.C., and Taga, M.E. (2013) Growth inhibition of Sporomusa ovata by incorporation of benzimidazole bases into cobamides. J Bacteriol 195: 1902-1911.

Moller, S., Croning, M.D.R., and Apweiler, R. (2001) Evaluation of methods for the prediction of membrane spanning regions. Bioinformatics 17: 646-653.

Möller, B., Oßmer, R., Howard, B.H., Gottschalk, G., and Hippe, H. (1984) Sporomusa, a new genus of gramnegative anaerobic bacteria including Sporomusa sphaeroides spec. nov. and Sporomusa ovata spec. nov. Arch Microbiol 139: 388-396. 
Ollivier, B., Cordruwisch, R., Lombardo, A., and Garcia, J.L. (1989) Isolation and characterization of Sporomusa acidovorans sp. nov., a methylotrophic homoacetogenic bacterium. Arch Microbiol 142: 307-310.

Oosterkamp, M.J., Veuskens, T., Talarico Saia, F., Weelink, S.A., Goodwin, L.A., Daligault, H.E., et al. (2013) Genome analysis and physiological comparison of Alicycliphilus denitrificans strains BC and K601T. PLoS ONE 8: e66971.

Pierce, E., Xie, G., Barabote, R.D., Saunders, E., Han, C.S., Detter, J.C., et al. (2008) The complete genome sequence of Moorella thermoacetica (f. Clostridium thermoaceticum). Environ Microbiol 10: 2550-2573.

Poehlein, A., Gottschalk, G., and Daniel, R. (2013) First Insights into the genome of the Gram-negative, endosporeforming organism Sporomusa ovata strain H1 DSM 2662. Genome Announc 1: e00734-13.

Postma, P.W., Lengeler, J.W., and Jacobson, G.R. (1993) Phosphoenolpyruvate: carbohydrate phosphotransferase systems of bacteria. Microbiol Rev 57: 543-594.

Punta, M., Coggill, P.C., Eberhardt, R.Y., Mistry, J., Tate, J., Boursnell, C., et al. (2012) The Pfam protein families database. Nucleic Acids Res 40: D290-D301.

Richter, M., and Rossello-Mora, R. (2009) Shifting the genomic gold standard for the prokaryotic species definition. Proc Natl Acad Sci USA 106: 19126-19131.

Rosenzweig, A.C., and Sazinsky, M.H. (2006) Structural insights into dioxygen-activating copper enzymes. Curr Opin Struct Biol 16: 729-735.

Sanders, C., Turkarslan, S., Lee, D.W., and Daldal, F. (2010) Cytochrome c biogenesis: the $\mathrm{Ccm}$ system. Trends Microbiol 18: 266-274.

Sass, H., Wieringa, E., Cypionka, H., Babenzien, H.D., and Overmann, J. (1998) High genetic and physiological diversity of sulfate-reducing bacteria isolated from an oligotrophic lake sediment. Arch Microbiol 170: 243-251.

Sauer, K., Harms, U., and Thauer, R.K. (1997) Methanol:coenzyme M methyltransferase from Methanosarcina barkeri. Purification, properties and encoding genes of the corrinoid protein MT1. Eur $J$ Biochem 243: 670-677.

Schut, G.J., and Adams, M.W. (2009) The iron-hydrogenase of Thermotoga maritima utilizes ferredoxin and NADH synergistically: a new perspective on anaerobic hydrogen production. J Bacteriol 191: 4451-4457.

Simpson, P.J., Richardson, D.J., and Codd, R. (2010) The periplasmic nitrate reductase in Shewanella: the resolution, distribution and functional implications of two NAP isoforms, NapEDABC and NapDAGHB. Microbiology 156: 302-312.

Stams, A.J.M., Van Dijk, J.B., Dijkema, C., and Plugge, C.M. (1993) Growth of syntrophic propionate-oxidizing bacteria with fumarate in the absence of methanogenic bacteria. Appl Environ Microbiol 59: 1114-1119.

Stupperich, E., and Konle, R. (1993) Corrinoid-dependent methyl transfer reactions are involved in methanol and 3,4-Dimethoxybenzoate metabolism by Sporomusa ovata. Appl Environ Microbiol 59: 3110-3116.

Stupperich, E., Eisinger, H.J., and Krautler, B. (1988) Diversity of corrinoids in acetogenic bacteria. p-cresolylcobamide from Sporomusa ovata, 5-methoxy6-methylbenzimidazolylcobamide from Clostridium formicoaceticum and vitamin B12 from Acetobacterium woodii. Eur J Biochem 172: 459-464.

Stupperich, E., Eisinger, H.J., and Krautler, B. (1989) Identification of phenolyl cobamide from the homoacetogenic bacterium Sporomusa ovata. Eur J Biochem 186: 657661.

Stupperich, E., Eisinger, H.J., and Albracht, S.P. (1990) Evidence for a super-reduced cobamide as the major corrinoid fraction in vivo and a histidine residue as a cobalt ligand of the p-cresolyl cobamide in the acetogenic bacterium Sporomusa ovata. Eur J Biochem 193: 105109.

Stupperich, E., Aulkemeyer, P., and Eckerskorn, C. (1992) Purification and characterization of a methanol-induced cobamide-containing protein from Sporomusa ovata. Arch Microbiol 158: 370-373.

Vignais, P.M., and Billoud, B. (2007) Occurrence, classification, and biological function of hydrogenases: an overview. Chem Rev 107: 4206-4272.

Wagner, U.G., Stupperich, E., Aulkemeyer, P., and Kratky, C. (1994) Crystallization and preliminary X-ray diffraction studies of a corrinoid protein from Sporomusa ovata. $\mathrm{J} \mathrm{Mol}$ Biol 236: 388-389.

Wagner, U.G., Stupperich, E., and Kratky, C. (2000) Structure of the molybdate/tungstate binding protein mop from Sporomusa ovata. Structure 8: 1127-1136.

Wang, S., Huang, H., Kahnt, J., and Thauer, R.K. (2013) Clostridium acidurici electron-bifurcating formate dehydrogenase. Appl Environ Microbiol 79: 6176-6179.

Zhang, Y., and Gladyshev, V.N. (2005) An algorithm for identification of bacterial selenocysteine insertion sequence elements and selenoprotein genes. Bioinformatics 21: 2580-2589.

Zhou, W., Das, A., Habel, J.E., Liu, Z.J., Chang, J., Chen, L., et al. (2005) Isolation, crystallization and preliminary X-ray analysis of a methanol-induced corrinoid protein from Moorella thermoacetica. Acta Crystallogr F Struct Biol Cryst Commun 61: 537-540.

Zuker, M. (2003) Mfold web server for nucleic acid folding and hybridization prediction. Nucleic Acids Res 31: 34063415.

\section{Supporting information}

Additional Supporting Information may be found in the online version of this article at the publisher's web-site:

File S1. Proteomic data of the proteins with peptide counts $>4$ of Sporomusa strain An4. The supporting information shows the predicted function of the proteins, the reference to the genome, and their related peptide abundance in the five different growth conditions: hydrogen and carbon dioxide $\left(\mathrm{H}_{2}\right.$ $\mathrm{CO}_{2}$ ), methanol $(\mathrm{MeOH})$, methanol and nitrate (NO3-), betaine $(B)$, and fructose $(F)$.

File S2. Neighbor joining tree constructed by using the amino acid sequences of the glycine/sarcosine/betaine reductase $B$ components of Eubacterium acidaminophilum and Sporomusa strain An4. The B components have an alpha and a beta subunit. The numbers at the branches are bootstrap percentage values. The scale bar represents $20 \%$ sequence difference. 